\title{
IDENTITAS DAN MOBILITAS SOSIAL PRIYAYI DALAM NOVEL PARA PRIYAYI KARYA UMAR KAYAM
}

\author{
Ahwan Fanani \\ Dosen FISIP Universitas Islam Negeri Walisongo Semarang \\ aristofanfanani@yahoo.com
}

\begin{abstract}
Novel with Javanese cultural setting is a phenomenon in Indonesian literary work. Umar Kayam in Para Priyayi provides vivid picture of the life of a specific Javanese aristocrat called priyayi from last period of Colonial to Independence Era. This article seeks to reveal identity and social mobility of priyayi, using sociology of literature approach. The article shows that Sastrodarsono, main character in the novel, is able to mobilize upward socially and attach to priyayi class as well as to its value, commitment and in-group feeling. Sosrodarsono who came from lower class in Javanese society was able to reach aristocrat status (priyayi) and built his own aristocrat dynasty. He internalizes priyayis' values and resocializes it to his family. The novel gives brief spectacle on social mobilization of Javanese aristocrat family and elements shaping the identity of priyayi. Kayam succesfully revives the priyayi life in his work so that his fiction contains cultural explanation just like anthropological works do.
\end{abstract}

Key words: Priyayi, sosial mobility, identity, cultural setting

\section{Pendahuluan}

Novel berlatar budaya Jawa sebenarnya bukanlah hal yang asing dalam dunia kesusasteraan di Indonesia. Ronggeng Dukuh Paruk atau Bekisar Merah karya Ahmad Thohari dan Pengakuan Pariyem karya Linus Sunardi adalah contoh-contoh novel yang menjadikan budaya Jawa sebagai latar sosial atau latar budayanya. Penggunaan budaya Jawa sebagai latar itu sebenarnya tidak terjadi begitu saja, melainkan karena adanya aktivitas kesusasteraan yang memiliki akar panjang dalam sejarah dan tradisi Jawa itu sendiri. Sejak abad ke-8 sastra Jawa telah berkembang dan terus berkembang sampai era modern. Pigeaud mencatat berbagai karya sastra Jawa yang lahir sejak abad ke-8 sampai abad ke-20, yaitu sampai masa modern (Pigeaud 1967). Semua itu menunjukkan bahwa kesusasteraan Jawa, yang mengambil nilai dari masyarakat Jawa, telah ada sejak masa lampau.
Novel Umar Kayam Para Priyayi sendiri bukan sebuah karya sastra Jawa yang dipengaruhi oleh teks-teks Jawa yang lahir pada masa lampau, melainkan upaya rekonstruksi kehidupan kelompok sosial tertentu di masyarakat Jawa. Novel Para Priyayi menyajikan sebuah potret kehidupan priyayi Jawa pada masa akhir kekuasaan Belanda di Indonesia sampai pada masa pemerintahan Orde Baru. Novel Para Priyayi menyajikan sebuah fiksi, tetapi dengan visi dan penggambaran budaya suatu kelompok sosial di masyarakat Jawa yang sangat kental.

Dalam novel ini, jarak estetis antara realitas dunia priyayi dan fiksi mengenai kehidupan priyayi perlu diposisikan secara tepat. Jelas bahwa karya Umar Kayam ini adalah berupa novel, berupa fiksi. Tokohtokohnya fiktif dan digambarkan dengan sudut pandang orang pertama para tokohnya. Namun keseluruhan kisah ini menggambarkan sebuah kultur yang ada padanannya dalam dunia nyata. 
Novel Umar Kayam memberikan gambaran langsung dan hidup mengenai dunia priyayi tersebut secara dinamis. Novel Para Priyayi menceritakan mengenai seorang priyayi yang berasal dari keluarga kelas bawa yang mampu mendirikan dinasti priyayi setelah ia berhasil menjadi ambtenaar (pegawai) pemerintahan Belanda dan menikahi anak seorang pegawai juga. Menjadi priyayi digambarkan oleh Kayam sebagai proses memasuki dunia identitas yang khas, dengan seperangkat kebiasaan dan nilai yang harus dianut. Selain itu, dunia priyayi digambarkan Kayam sebagai dunia dinamis sehingga status priyayi bukan sebagai ascribed/ given (diterima apa adanya), melainkan juga status yang achieved (diperoleh melalui mobilitas sosial).

Kentalnya nuansa budaya novel Para Priyayi, menjadi obyek garapan yang menarik untuk kajian bahasa, sastra, maupun budaya. Abdul Rochman (2014) menulis artikel tentang "Stilistika Novel Para Priyayi Karya Umar Kayam." Artikel tersebut menekankan kepada bahasa diksi, gaya kalimat, kiasan, citraan, dan sarana retoris novel. Sementara itu, Setiadi, Aksa dan Adji (2013: 69-80) lebih tertarik dengan dimensi sosial dan budaya novel tersebut. Mereka mengkaji konsep kepriyayi-an dalam novel Para Priyayi melalui perbandingan dengan novel Gadis Pantai karya Pramooedya Ananta Toer. Ketiga penulis memfokuskan tulisannya pada konsep, jenis, dan pola kepercayaan priyayi. Ada pula penelitian tesis mengenai novel Para Priyayi dengan fokus pada persoalan nilai pendidikan dengan pendekatan sosiologi sastra sebagaimana dilakukan oleh Moersito (2008).

Berbagai tulisan di atas menegaskan bahwa novel Para Priyayi memiliki daya tarik bagi para pengkaji. Hal itu menunjukkan kekuatan novel tersebut dalam bidang dimensi bahasa, sastra, dan budaya menjadi kekuatan tersendiri dalam novel tersebut.

Tulisan ini adalah upaya kajian sastra dengan pendekatan sosial-budaya, yang secara khusus akan menyoroti bagaimana identitas priyayi dipahami oleh para pelakunya dan bagaimana mobilitas sosial itu terjadi di kalangan priyayi, sebagai sebuah kelompok atau strata sosial. Identitas adalah persoalan mengenai siapa saya, yaitu pertanyaan mengenai diri sendiri dalam kaitannya dengan pihak lain.

Tajfel, sebagaimana dikutip oleh Ashmore, Jussim, dan David (2001: 6), mendefinisikan identitas sebagai "bahagian dari konsep diri individu yang berasal dari pengetahuannya mengenai keanggotaannya dalam suatu kelompok atau berbagai kelompok bersamaan dengan nilai dan kepentingan emosional yang tertanam dalam keanggotaan tersebut. Identitas sosial mengandung dua elemen penting, yaitu 1) keyakinan bahwa seseorang termasuk dalam suatu kelompok dan 2) pentingnya keanggotaan dalam kelompok tersebut bagi diri seseorang. Jadi, identitas sosial menyangkut makna diri dalam suatu kelompok beserta nilai dan emosi yang menyertainya.

Sementara itu, mobilitas sosial mengacu kepada proses kluster komitmen sosial, ekonomi, dan psikologi lama mengalami erosi atau rusak dan orang menjadi terbuka bagi popa sosialisasi dan perilaku baru. Proses tersebut melalui dua tahap, yaitu: 1) pencabutan dari latar, perilaku, dan komitmen lama dan 2) masuknya orang yang termobilisasi ke dalam pola keanggotaan kelompok baru yang stabil (Deutsch 1961: 494).

Dengan demikian, kajian mengenai mobilitas sosial termasuk pula melihat bagaimana terjadinya perubahan komitmen keanggotaan dari kelompok lama kepada kelompok yang baru. Priyayi, sebagai suatu kelas dan status sosial, merupakan bentuk dari kelompok sosial sehingga ada komitmen nilai dan ikatan emosional di 
antara anggotanya sehingga mobilitas sosial dalam konteks ke-priyayi-an melibatkan perubahan komitment dari kelompok nonpriyayi kepada priyayi atau mungkin sebaliknya.

Penelitian ini menggunakan sosiologi sastra dengan berpijak dari teks dan bergerak kepada pemahaman dimensi luar teks atau sebaliknya. Sosiologi sastra, menurut Damono (2013: 2-3) adalah pendekatan terhadap sastra yang mempertimbangkan segi-segi kemasyarakatan, baik dengan cara bergerak dari faktor-faktor di luar sastra untuk membicarakan sastra maupun dari struktur teks dan kemudian mempergunakan isi teks untuk memahami gejala sosial di luar teks. Penggunaan sudut pandang orang pertama novel ini sangat membantu pembaca untuk melihat dimensi identitas itu dari perspektif insider, meskipun pelakunya fiktif, dan kemudian dibaca dengan pendekatan teori kebudayaan sehingga melahirkan pula perspektif outsider. Pembacaan terhadap novel Para Priyayi dengan pendekatan kebudayaan memungkinkan dimensi budaya yang kental dalam novel ini terapresiasi.

Meskipun novel pada dasarnya adalah fiksi, namun novel ini menggambarkan dunia priyayi yang memiliki dasar pada fakta sosial di kalangan masyarakat Jawa, pada masa lampau. Pengungkapan aspek mobilisasi sosial dan identitas ke-priyayi-an akan membantu pembaca untuk menyelami kehidupan para priyayi, yang hidup pada peralihan masa pemerintahan Hindia Belanda sampai masa-masa kemerdekaan.

\section{Kisah Keluarga Priyayi}

Novel Para priyayi bercerita mengenai keluarga besar Sastrodarsono, seorang mantri guru. Sastrodarsono adalah anak Atmokasan, seorang petani dari Kedungsimo, daerah antara Madiun dan Surakarta. Ia anak petani yang menggarap sawah seorang priyayi, Ndoro Seten. Meskipun Bapaknya petani desa, tetapi ia ingin anaknya bersekolah dan tidak segansegan menghukum anaknya bila membandel dan hanya mau ke sawah saja. Sastrodarsono adalah nama yang diberikan oleh Ndoro Seten, karena ibunya sebenarnya merasa keberatan memberi nama anaknya dengan nama yang lebih hanya cocok untuk seorang priyayi. Ndoro Seten menghargai kejujuran Atmokasan dalam menggarap sawahnya sehingga ia bersedia melobi Ndoro Wedono dan Priyagung Madiun agar Darsono bisa magang sebagai mantri guru.

Setelah menjadi priyayi, orang tua Darsono berinisiatif menikahkan Darsono dengan Siti Aisyah (Ngaisah), anak mantri candu dari Jogorogo. Darsono dicarikan keluarga yang sepadan dengan status barunya sebagai priyayi. Ngaisah inilah yang mendampingi Darsono dan melahirkan anak-anak penerus trah priyayi, yang ia baru ia mulai dari dirinya sendiri karena keluarganya hanyalah seorang petani dengan sawah yang kecil. Darsono menjadi guru di Wanagalih Madiun.

Sebagai priyayi, Darsono berkewajiban pula menampung anak-anak kerabatnya yang menitipkan anak-anak mereka agar didik oleh Darsono. Ada Ngadiman, Sri, Darmin dan Soenandar, yang merupakan kerabat dari Darsono maupun Ngaisah. Sri dan Darmin hanya bertahan sampai kelas lima ikut keluarga Darsono. Mereka berasal dari latar belakang keluarga santri, namun oleh keluarganua dijemput kembali oleh keluarganya karena mereka mengkawatirkan pendidikan agama anakanaknya, terlebih mereka diganggu oleh Soenandar. Soenandar sendiri adalah anak orang miskin yang ibunya kemudian meninggal dunia. Darsono berupaya keras agar Soenandar berhasil dan bisa menjadi guru sepertinya. Oleh karena itu, ketika Darsono membuat sekolah swasta di 
Wanalawas, Nandar lah yang ia minta menjadi guru.

Sayangnya, sejak kecil Soenandar sangat bandel sehingga ketika menjadi guru pun ia masih bandel dan menghamili anak ibu kostnya dan lalu melarikan diri dan memilih untuk menjadi anggota perampok. Ia akhirnya tewas di tangan polisi. Dari Nandar inilah lahir Lantip, yang kelak dibesarkan oleh Darsono, yang ternyata mampu mewarisi sikap dan martabat seorang priyayi serta membantu keluarga Darsono dalam situasi-situasi genting.

Darsono dikaruniai tiga orang anak, yaitu Noegroho, Hardojo, dan Soemini. Anak pertama Darsono adalah Noegroho. Ia awalnya bekerja sebagai guru di Sekolah Rakyat Sempurna di Jetis. Setelah kedatangan tentara Jepang, ia ikut dalam tentara Pembela Tanah Air (PETA) dan akhirnya menjadi jenderal pada masa kemerdekaan. Anak lelakinya, Toni, menjadi korban revolusi akibat ditembak tentara Belanda. Anak perempuannya, Marie, bekerja di perusahaan.

Hardojo mengikuti jejak Darsono, menjadi guru. Ia awalnya menjadi guru HIS di Wonogiri kemudian bekerja untuk Istana Mangkunagara untuk mengurus kantor baru yang bergerak dalam pendidikan orang dewasa dan gerakan pemuda. Ia menikah dengan Sumarti anak pensiunan Panewu (sederat dengan dengan asisten wedana). Dari pernikahan tersebut, ia dikaruniani seorang anak Harimurti, yang cerdas dan peka masalah sosial, namun terbelit masalah karena aktivitasnya di lembaga seni yang berafisilasi kepada PKI.

Soemini adalah sosok anak perempuan maju, yang selepas sekolah HIS melanjutkan sekolah van Deventer. Ia menikah dengan Raden Harjono Cokrokoesoemo, seorang asisten wedana, tamatan OSVIA, yang pada era kemerdekaan menjabat sebagai kepala jawatan di Kementerian Dalam Negeri.
Jadi, Darsono berhasil untuk meletakkan landasan bagi lahirnya keluarga para priyayi. Ia meninggal di masa tuanya. Lantip yang didaulat oleh keluarga untuk mewakili mereka dalam memberikan sambutan bagi upacara pemakaman Sosrodarsono. Novel ini diakhiri dengan kenyataan bahwa dinasti priyayi yang diletakkan oleh Sastrodarsono tetap hidup karena anak maupun cucunya memperoleh kedudukan maupun kelas sosial yang baik, namun ada persoalan nilai dan komitmen pada etika ke-priyayi-an yang tidak mudah dipertahankan dalam perubahan sosial. Lantip, meskipun memiliki latar bukan dari keturunan Sastrodarsono dan bukan sosok dengan kelas sosial tinggi, mampu memelihara dan berkomitmen kepada nilai-nilai yang dulu dianut oleh para priyayi.

\section{Identitas dan Mobilitas Sosial Priyayi}

Dunia priyayi adalah dunia dari suatu kelompok sosial dalam masyarakat Jawa. Clifford Geertz dalam karya monumentalnya The Religion of Java memasukkan priyayi sebagai salah satu kelompok sosial dalam masyarakat Jawa. Priyayi berasal dari kelompok aristokrat pada masa kerajaan di Nusantara, yang pada masa kekuasaan Belanda diambil alih menjadi pegawai negeri yang diangkat dan diberi gaji. Kelompok ini menurut Geertz adalah elit kerah putih, yang memelihara etiket kraton, yaitu seni-seni canggih dalam tari, drama, dan musik (Geertz 1960: 6). Geertz memasukkan priyayi sebagai varian kebudayaan Islam-Jawa, yaitu varian kebudayaan yang kuat dipengaruhi tradisi filsafat Hinduisme.

Priyayi pada dasarnya adalah elit masyarakat Jawa. Priyayi terbagi menjadi dua kategori, yaitu priyayi dari keturunan raja dan bangsawan dan priyayi dari nonbangsawan yang utamanya naik status karena pekerjaan. Pada waktu Raja Jawa masih efektif memegang kekuasaan, priyayi berada dalam strata di bawa raha. 
Jika kraton dan raja menjadi pusat kehidupan sosial, maka di bawah raja ada para bangsawan, para priyayi, dan kemudian masyarakat umum (Soeratman 2000: 209). Akan tetapi, ketika kekuasaan Belanda semakin kuat menghegemoni kehidupan masyarakat Jawa, priyayi tidak selalu berada di bawah raja. Para priyayi adalah mereka yang menduduki jabatan dan posisi di pemerintahan.

Koentjaraningrat memasukkan priyayi sebagai kelas tertinggi dalam masyarakat, sebelum perang dunia II. Priyayi terbagi menjadi dua kategori, yaitu priyayi Pangreh Praja, yaitu priyayi dari kalangan pejabat pemerintahan yang memiliki kedudukan karena kebangsawanannya, dan priyayi bukan Pangreh Praja, yaitu golongan terpelajar dari kalangan bawah yang mencapai kedudukan pegawai negeri karena pendidikan (Koentjaraningrat 1984: 234).

Proses menjadi priyayi sendiri melalui proses-proses tertentu. Ada jalur suwita dan jalur magang yang harus ditempuh oleh calon priyayi. Suwita dilaksanakan pada sekitar usia dua belas tahun, yaitu seorang anak diikutkan di rumah kerabat yang telah menjadi priyayi tingkat tinggi. Ia melakukan kerja kasar maupun kerja lain seraya mempelajari sopan santun dan kebudayaan priyayi, seperti menunggang kuda, senjata, sastra, seni, dan keterampilan lain. Jika lolos tahap suwita, ia masuk tahap magang, yaitu dikirim ke salah satu bagian dalam struktur pemerintahan lokal atau kraton. Untuk bisa magang, perlu ada rekomendasi atau surat silsilah dari priyayi tempat ia suwita (Soeratman1989: 67-68).

Dalam novel Para Priyayi, sosok Sastrodarsono pun berasal dari kalangan petani di Wanagalih, sebuah wilayah di Madiun. Tempat ini dipilih oleh pengarang bukannya tanpa alasan karena Madiun adalah salah satu daerah strategis pada masa kerajaan, masa kekuasaan Belanda, dan pada awal kemerdekaan. Pada masa kekuasaan Mataram, Madiun adalah tempat para Pangeran yang memberontak kepada kekuasaan raja di Solo. Madiun menjadi jalur trans Jawa yang menghubungkan Surabaya dengan Jawa Barat. Madiun menjadi wilayah pertanian dan perkebunan, kota politik dan pergerakan, dan tempat pendidikan bagi para priyayi. Di sinilah berkembang kebudayaan priyayi yang canggih (Anderson 2003: 49-50).

Sastrodarsono bisa menjadi priyayi berkat pendidikan yang ia peroleh atas bantuan dari Ndoro Seten. Ia pun bisa magang karena rekomendasi dari Ndoro Seten. Ia masuk ke dalam lingkaran priyayi, yang menjadi bagian dari administrasi pemerintahan Hindia Belanda. secara bertahap, Sastrodarsono membangun dinasti priyayi. Anak-anaknya menjadi priyayi dan ia juga juga menjadi tempat suwita beberapa anak saudaranya, termasuk ayah Lantip dan Lantip sendiri.

Anak Sastrodarsono, Hardojo misalnya, bekerja sebagai guru Gupernemen (pemerintah Hindia Belanda) dan menjadi priyayi dalam birokrasi pemerintahan Hindia Belanda. Namun, ia berpindah untuk mengabdi kepada istana Mangkunegara, dan menjadi priyayi abdi istana (h. 170-172). Hal itu menunjukkan bahwa status priyayi dalam novel ini mengacu kepada dua kemungkinan, yaitu kalangan elit di masyarakat sebagai abdi pemerintah Gupernemen atau abdi kraton, baik Kasunanan, Mangkunegaran, maupun Kasultanan.

Hal yang patut dicatat adalah bahwa priyayi sebagai sebuah strata sosial, sebagai sebuah elit sosial memiliki keterbukaan untuk dimasuki oleh kalangan bawah. Ada keterbukaan bagi mobilitas sosial dalam strata ini. Mobilitas sosial adalah keterbukaan pergerakan naik atau turun dalam strata sosial, baik dalam kelompok kelas maupun status (Waters and Crook 1990: 165-166). 
Kasus Sastrodarsono menjadi bukti bagaimana kalangan bawah, dari kalangan petani, bisa mencapai strata priyayi. Hal itu tampak dari nasehat Ndoro Seten, priyayi yang telah menyekolahkan Sastrodarsono dan mengusahakannya agar bisa menjadi guru:

"Kau tahu Le. Ini langkah yang sangat penting dalam hidupmu. Kau mulai masuk dalam kalangan priyayi. Kau bukan petani lagi. Diingat-ingat itu, Le. Duniamu mulai sekarang akan lain. Tahulah membawa diri dalam dunia yang baru itu. Kalau kau hati-hati, jujur, dan setia kepada atasan dan peraturan Gupernemen pasti kau akan berhasil naik pangkat. Jalan menuju dunia priyayi sekarang ada di depanmu, Le."

Saya mendengarkan petuah Ndoro Seten itu dengan penuh perhatian. Alangkah berbobot dan benar belaka nasehat itu. Saya akan memasuki dunia priyayi yang akan lain dari dunia saya sebelumnya, dunia petani. saya berjanji di dalam hati akan dengan sekuat tenaga masuk menyesuaikan diri dengan dunia yang baru ini” (Kayam, 2012: 42).

Kutipan di atas menegaskan bahwa dunia priyayi tidak sama dengan dunia petani. Dunia priyayi berada di strata atas dibandingkan petani. Namun, Sastrodarsono, yang berasal dari keluarga petani bisa memasuki dunia tersebut. Pintu untuk melakukan mobilitas ke atas status sosial ini dimulai dari pendidikan, promosi jabatan, dan pernikahan. Sastrodarsono setelah lulus sekolah desa lima tahun dibantu oleh Ndoro Seten untuk dapat magang menjadi guru bantu. Hal itu menunjukkan bahwa pendidikan adalah alat utama untuk memasuki dunia priyayi. Setelah itu, baru adanya rekomendasi dari satu priyayi agar anak dari kalangan bawah yang sudah menyelesaikan studi bisa diterima bekerja di kantor atau sebagai abadi gupernemen. Setelah itu terjadi, barulah anak dari kalangan bawah layak dipandang sebagai priyayi. Untuk menyempurnakan status priyayi, hal terakhir yang dibutuhkan adalah pernikahan dengan anak dari keluarga priyayi juga.

Gengsi status priyayi itu pun mengalami mobilitas. Pada zaman Belanda, priyayi adalah status yang tinggi, dihormati, dan dengan gaji yang cukup untuk menopang gaya hidup priyayi tersebut. Kondisi itu tidak bertahan pada masa Jepang. Semua orang, baik pemuka agama, tokoh masyarakat, dan guru diharuskan mengikuti pelatihan militer bersama para pemuda. Kondisi hidup para guru mengalami penurunan drastis, sebagaimana tampak dalam keluhan Noegroho yang menjabat sebagai guru HIS ketika Jepang datang:

“.....Sebelum Jepang datang kami memang cenderung hidup agak mewah. Maklum gaji guru sekolah Gupernemen yang seratus lima puluh gulden itu memang lebih dari cukup untuk menyangga kehidupan kami. Isteri saya yang agak senang dengan makanan cara Belanda, karena biasa dimanjakan ibunya yang pensiunan juru rawat Rumah Sakit Elizabeth, jadi agak terpukul dengan keadaan yang merosot itu. Langkahlangkahnya sebagai ibu rumah tangga jai kikuk menghadapi keadaan yang serba kurang itu" (Kayam, 2012: 196).

Jadi, mobilitas sosial priyayi bisa terjadi secara individual, yaitu naik atau turunnya status dan kelas individu, baik memasuki atau meninggalkan dunia priyayi, namun bisa juga mobilitas itu terjadi secara umum akibat perubahan sosial yang terjadi.

Kelebihan novel Para Priyayi ini adalah kemampuannya dalam menggambarkan perkembangan dunia priyayi dari sudut pandang keluarga 
Sastrodarsono dari masa Belanda, masa Jepang, dan masa Kemerdekaan. Perubahan sosial dan politik ternyata menjadi variabel penting yang menentukan gengsi dari strata sosial seorang priyayi.

Pada masa Belanda, identitas priyayi sangat jelas. Para priyayi memiliki beberapa kode sosial yang membuat mereka bisa dikenal sebagai priyayi. Pertama adalah pendidikan dan pekerjaan. Para priyayi adalah lulusan sekolah Belanda yang bekerja kepada pemerintah Hindia Belanda, tentu bukan untuk pekerjaan kasar, melainkan pekerjaan yang bersifat administratif atau fungsional. Kedua, priyayi memiliki budaya khas, yang menunjukkan kelas mereka. Ketika pertama menjadi priyayi, Sastrodarsono berusaha mempelajari cara hidup priyayi dari Ndoro Seten. Ia memperhatikan kebiasaan seorang priyayi, sebagaimana tampak dalam kutipan berikut:

“... Dunia priyayi pernah saya amati dari jarak yang sangat dekat. Dan dunia Ndoro Seten di Kedungsimo adalah dunia priyayi. Meskipun dari suatu jarak, dunia itu saya kenal dan tidak pernah lupus dari pengamatan saya. Kebiasaan Ndoro Seten seharihari, pagi berjalan-jalan atau naik kursi goyang, sambil minum kopi dan makan pisang goreng serta kuwih jajanan pasar. Kemudian beliau akan mandi, dahar sarapan yang terdiri dari nasi dengan lauk pauk yang begitu banyak memenuhi meja. Kemudian beliau akan duduk di ruang kantoran, di pendopo membaca laporan-laporan yang dibawa opas. Atau, kalau tidak, beliau akan naik dokar pergi ke kawedanan di Bangsri dan baru pulang pada sore hari..." (Kayam, 2012: 42).

Priyayi memiliki kebiasaan-kebiasaan yang menunjukkan status dan kelas sosialnya.
Suasana rumah maupun pergaulan menjadi salah satu budaya seorang priyayi. Aisyah sangat membantu Sastrodarsono untuk menciptakan kebiasaan priyayi karena kecakapan Aisyah dalam mengelola rumah tangga dan tata cara kehidupan priyayi. Pergaulan Sastrodarsono juga tidak lepas dari kalangan priyayi. Ia mengikuti kebiasaan ceki (main kartu) yang menjadi sarana komunikasi dan keakraban para priyayi.

Pada kenyataannya, priyayi memang memiliki pola rekreasi dan kegiatan yang secara sosial harus mereka lakukan, seperti menghadiri undangan-undangan pernikahan, khitanan atau tedak siten yang dilakukan oleh sesama priyayi, untuk kebutuhan komunikasi dan kelancaran tugas-tugasnya. Mereka juga perlu mengikuti pertunjukan dalam kegiatan tersebut, seperti wayang atau tayuban, meskipun semalam suntuk. Main kartu juga menjadi sarana hiburan dan komunikasi. Meskipun permainan kartu itu hanya untuk kesenangan, tidak jarang disertai dengan perjudian. Ada pula kebiasaan priyayi yang ilmiah, seperti saraseyan untuk mendiskusikan persoalan filsafat, moral, sastra, maupun politik (Koentjaraingrat 1984: 286-287).

Ketiga, budaya priyayi didasari pula oleh cara berbahasa dan bersikap secara halus. Priyayi harus mampu untuk membawa diri dan mengendalikan perasaan. Jadi, selain faktor pendidikan dan gaya hidup, ada pula sebuah norma yang harus ditunjukkan oleh priyayi, khususnya dari gaya bahasa dan tingkah laku.

Dunia kepriyayian adalah kelompok status, dengan kelas ekonomi sebagai pendukung sekunder. Status selalu diikuti dengan peran, yaitu mengenai apa yang harus dilakukan dan tidak boleh dilakukan oleh pemegang status tersebut. ayah Sastrodarsono, Atmokasan berpesan kepada anaknya: "Jadi priyayi itu jadi orang terpandang di masyarakat, bukan 
jadi orang kaya. Priyayi itu terpandang kedudukannya karena kepinterannya. Kalau mau jadi kaya ya jadi saudagar, jadi bakul saja (h. 52)." Pesan Atmokasan ini menunjukkan secara jelas bahwa priyayi merupakan sebuah status sosial, bukan sekedar kelas yang dibangun di atas landasan ekonomi.

Suatu kelompok elit adalah bagian dari stratifikasi sosial di masyarakat. Elit adalah kelompok dengan kekuatan lebih untuk memberikan perintah. John Meisel memberikan tiga elemen penting kelompok elit, yaitu: 1) kesadaran mengenai keberadaan dan keanggotaan mereka dalam kelompok tersebut, 2) koherensi dalam bertindak sesuai dengan kepentingan mereka, dan 3) konspirasi, atau adanya pertukaran informasi dan evolusi strategi bersama untuk melanjutkan kepentingan kelompok (Waters and Crook 1990: 177).

Para priyayi dalam novel ini umumnya memiliki tiga elemen penting sebagai kelompok elit. Kesadaran sebagai priyayi hadir dalam diri Sastrodarsono begitu diangkat menjadi guru magang. Ia juga memiliki kesadaran untuk membangun dinasti priyayi dengan menjadikan anak-anaknya sebagai priyayi. Lingkungannya mulai menempatkan dia dalam posisi sebagai priyayi. Ia pun dituntut untuk bisa bertingkah laku dan bertutur kata laiknya seorang priyayi.

Terakhir, ada pula sarana konspirasi para priyayi untuk berbagai informasi dan mengukur cara pandang mereka mengenai suatu persoalan, yaitu melalui permainan kartu Cina (Pei dan Ceki) sebagai kesenangan. Sastrodarsono ketika mulai bergaul dengan dunia priyayi mendapatkan sarana untuk bisa mendapatkan elemen konspirasi di kalangan elit priyayi melalui permainan kartu cina tersebut.

“......Lewat bermain kartu cina inilah kami mengobrol dan bergunjing tentang berbagai hal yang terjadi di Wanagalih, bahkan yang terjadi di seluruh Karesidenan Madiun. Pengalaman saya yang masih hijau dalam pekerjaan serta pergaulan di masyarakat priyayi pemerintahan benar-benar mendapat tambahan pengetahuan di percakapan sekitar meja bundar permainan ceki dan pei itu. Apalagi tentang pergunjinganpergunjingan laku serong serta permainan uang di kalangan priyayi pemerintahan" (Kayam, 2012: 54).

Pelanggengan status priyayi secara tidak langsung dilakukan melalui hobi dan hubungan sosial di kalangan para priyayi.

Sarana pelanggengan kelompok elit ini juga terjadi melalui pernikahan antara sesama keluarga priyayi. Ketika Sastrodarsono menjadi guru, ia dicarikan jodoh yang sepadan, yaitu anak dari keluarga priyayi. Karena status priyayi terkait pula dengan pengaturan rumah, pasangan hidup dari kalangan priyayi-lah yang mampu menjalankan fungsi tersebut. Hal itu dirasakan sendiri oleh Sastrodarsono ketika menikah dengan Ngaisah:

".....Dik Ngaisah, alhamdulilah, adalah istri seperti yang saya harapkan semula. Ia adalah perempuan yang agaknya, memang sudah disiapkan orang tuanya untuk menjadi istri priyayi yang mumpuni, lengkap akan kecakapannya dan keprigelannya. Di dapur ia tidak hanya tahu memasak, tetapi juga memimpin para pembantu di dapur. Wibawa kepemimpinannya dalam pekerjaan mengatur rumah tangga langsung terasa. Dalam mengatur meja makan serta kamar tidur dan menaruh kursi dan meja di ruang depan dan ruang dalam jelas Dik Ngaisah lebih berpengalaman dari saya. Segera saja terlihat bagaimana bekas tangan rumah tangga priyayi melekat pada semua yang disentuhnya" (Kayam, 2012: 49). 
Kutipan di atas menunjukkan bahwa dunia priyayi memiliki norma tersendiri. Ada seperangkat tuntutan yang lahir dari status sebagai priyayi, khususnya tentang bagaimana harus menempatkan diri dan menunjukkan sikap yang sejalan dengan status tersebut. Semua itu menunjukkan bahwa priyayi adalah identitas sosial yang cukup kuat membentuk sikap individu yang memiliki identitas tersebut.

Identitas priyayi daam novel ini diceritakan sebagai identitas yang khas, yang terbentuk oleh stratifikasi sosial di masyarakat Jawa, sebagai warisan dari tradisi kerajaan Hindu di masa lampau. Meskipun sistem kerajaan dan kekuasaan Hindia Belanda melemah dan menghilang serta semakin mudahnya posisi birokrasi diakses oleh masyarakat umum pada masa Republik, namun etos dan etika priyayi masih memiliki pengaruh di kalangan kelompok kerah putih. Sebagaimana diungkapkan oleh Geertz, kesopanan dan seni yang tinggi masih menjadi karakteristik elit sosial dan menjadi model bagi elit maupun keseluruhan masyarakat (Geertz 1960: 6).

Apa yang dikemukakan oleh Geertz bisa diterima setidaknya sebelum era Reformasi. Saat ini, status priyayi semakin lama semakin tergerus oleh perubahan zaman dan akses komunikasi yang semakin terbuka. Akan tetapi, semangat dan aspirasi untuk mendaki strata sosial yang lebih tinggi dengan mengambil budaya tertentu masih menjadi bagi umumnya masyarakat Indonesia yang ingin naik kelas dan naik status, meskipun bentuk dari perwujudan mobilitas dan identitas itu sudah banyak berubah.

\section{Penutup}

Novel Para Priyayi adalah sebuah potret masyarakat Jawa yang terabadikan dan terhidupkan melalui fiksi. Umar Kayam memiliki wawasan dan kemampuan untuk menjadikan dunia priyayi itu terpotret secara jelas dan dinamis sehingga pembaca bisa merasakan dan menghayati bagaimana para insider kelompok sosial ini mendefinisikan diri mereka sendiri dan bagaimana mereka berusaha untuk mencapai atau mempertahankan status tersebut. Penggunaan fiksi untuk menggambarkan realitas sosial memang bukan barang baru dalam dunia sastra. Akan tetapi, kedalaman visi dan wawasan kebudayaan pengarang akan menentukan cita rasa dan nuansa yang hidup dalam karyanya.

Umar Kayam secara meyakinkan mampu meramu latar budaya, perkembangan politik, dan dinamika keluarga priyayi dalam jalinan kisah yang utuh, solid, dan hidup. Kemampuan inilah yang membuat novel Para Priyayi layak masuk sebagai novel "serius" dalam dunia sastra di Indonesia.

Tulisan di atas menegaskan bahwa identitas priyayi dibangun di atas serangkaian tata cara, pendidikan, sampai kepada hiburan. Ada kesadaran bersama di kalangan para priyayi untuk memelihara etika priyayi. Identitas itu mereka tanamkan kepada keluarga, anak, dan kerabat yang ingin masuk ke dunia priyayi. Dunia priyayi terbuka bagi mobilitas sosial. Sastrodarsono adalah contoh kalangan bawah yang mengalami mobilitas sosial sehingga bisa masuk ke dalam kelompok sosial priyayi. Proses mobilitas sosialnya dilakukan melalui mekanisme suwita yang dibimbing oleh Ndoro Seten dan magang atas rekomenasi Ndoro Seten. Setelah masuk dunia priyayi, ia harus menyesuaikan sendiri nilai dan kebiasaan para priyayi serta meletakkan landasannya dalam keluarga bagi anak anak-anaknya.

\section{Daftar Pustaka}

Anderson, David Charles. 2003. Peristiwa Madiun 1948: Kudeta atau Konflik Inernal Tentara? Yogyakarta: Media Pressindo. 
Ashmore, Richard D, Lee Jussim, David Wilder (eds.). 2001. Social Identity, Intergroup Conflict, and Conflict Reduction. Oxford: Oxford University Press.

Damono, Sapardi Djoko. 2013. Sastra Bandingan. Ciputat: Editum.

Deutsch, Karl W. 1961. "Social Mobilization and Political Development." The American Political Science Review Vol. 55. No. 3 (September) as republished by www.jstor.org

Geertz, Clifford. 1960. The Religion of Java. Chicago: The University of Chicago Press.

Kayam, Umar. 2012. Para Priyayi, Sebuah Novel. Jakarta: PT Pustaka Utama Grafiti. Cet. XIV.

Koentjaraningrat. 1984. Kebudayaan Jawa. Jakarta: PN Balai Pustaka.

Moersito, A. Eny. 2013. "Perbandingan Nilai-Nilai Pendidikan Budaya Jawa dalam Novel Para Priyayi Karya Umar Kayam dan Novel Canting Karya Arswendo Atmowiloto (Sebuah Telaah dengan Pendekatan Sosiologi Sastra). Tesis Program Pascasarjana Universitas Sebelas Maret Surakarta.

Pigeaud, Theodore G.Th. 1967. Literature of Java: Synopsis of Javanese Literature 900-1900 A.D. Leiden: KITLV.

Rochman, Abdul. 2014. "Stilistika Novel Para Priyayi Karya Umar Kayam." Nosi Volume 2, Nomor 3 Agustus.

Setiadi, David. Yati Aksa, dan M. Adji. 2013. "Konsep Ke-Priyayi-an yang Terefleksi dalam Novel Para Priyayi Karya Umar Kayam dan Gadis Pantai Karya Pramoedya Ananta Toer." Jurnal Widyaparwa, Volume 41 Nomor 1 Juni 2013.

Soeratman, Darsiti. 2000. Kehidupan Dunia Keraton Surakarta 18301939. Yogyakarta: Yayasan untuk Indonesia.
Waters, Malcolm and Rodney Crook. 1990. Sociology One. Melbourne. Longman Chesire. 